\title{
EL ENTUSIASMO DE LA REVOLUCIÓN. SOBRE LA FILIACIÓN KANTIANA DEL ÚLTIMO FOUCAULT
}

\author{
José Luis López DE LIZAGA \\ Universidad de Zaragoza \\ http://dx.doi.org/10.15304/ag.38.1.5010
}

\section{Resumen}

Este artículo se pregunta si los últimos escritos de Foucault, pertenecientes ya a la década de 1980, superan el déficit normativo que autores como Nancy Fraser o Jürgen Habermas habían criticado en la obra foucaultiana anterior. Y se argumenta que los últimos textos siguen siendo vulnerables a esas críticas, a pesar del giro hacia la cuestión ética del "cuidado de sí” y a pesar de la reivindicación del legado kantiano e ilustrado. En esta argumentación, la comparación de las ideas de Foucault y Kant sobre las revoluciones y su legitimidad es determinante para comprender las dificultades normativas de la producción foucaultiana tardía.

Palabras clave: poder, revolución, legitimidad, Estado de derecho, Kant, Foucault.

\section{Abstract}

This article analyses whether the last writings of Foucault, already belonging to the 1980s, overcome the normative deficit that authors like Nancy Fraser or Jürgen Habermas had criticized in the Foucauldian previous work. And it is argued that the latest texts are still vulnerable to these criticisms, despite the shift towards the ethical issue of "self-care" and despite the claim of a Kantian and enlightened legacy. In this discussion, the comparison of Foucault's and Kant's ideas about revolutions and their legitimacy is crucial to understanding the normative difficulties of late Foucauldian production.

Keywords: power, revolution, legitimacy, constitutional State, Kant, Foucault.

Recibido: 13/03/2018. Aceptado: 29/05/2018. 
Con la publicación en 1981 de un ensayo titulado "Foucault on Modern Power: Empirical Insights and Normative Confusions", Nancy Fraser escribió un capítulo memorable de esa querella de modernos y posmodernos que animó los debates académicos de los años ochenta y noventa del siglo XX. ${ }^{1}$ En aquel ensayo, Fraser argumentaba que la teoría de la sociedad de Foucault contenía intuiciones empíricas muy valiosas, pero mostraba también una falta de claridad en sus fundamentos normativos que la hacía, en conjunto, difícilmente aceptable. En opinión de Fraser, las empirical insights más destacables de la obra foucaultiana se referían a la naturaleza y el funcionamiento del poder en la sociedad contemporánea. En estudios como Vigilar y castigar o el primer volumen de la Historia de la sexualidad, Foucault logró superar la tradicional concepción represiva del poder, quizás correcta para comprender el funcionamiento de la sociedad premoderna o del Antiguo Régimen, pero obsoleta por lo que respecta a la sociedad occidental desde finales del siglo XVIII o principios del XIX. En efecto, el poder de la sociedad premoderna era un poder esencialmente represivo, centralizado y jerarquizado, dependiente en última instancia de la voluntad de un monarca y ejercido a menudo de una forma brutal, por ejemplo en esas ejecuciones públicas y ejemplarizantes como la que describe Foucault en las primeras páginas de Vigilar y castigar. Pero esta imagen cambia desde finales del siglo XVIII, debido a las necesidades funcionales de control y administración de sociedades de masas. El poder dejó de ser represivo y comenzó a ser más bien productivo: un poder que no asfixia o impide, sino que genera conductas e incluso formas de "subjetividad" o de autocomprensión de los sujetos sometidos a él. Su eficacia se incrementa al dejar de estar centralizado y jerarquizado para pasar a ser un poder omnipresente, reconocible (aunque no siempre a simple vista) en todas partes, en toda relación social, en toda interacción. Y si el poder de la sociedad premoderna se ejercía por medio de leyes, este nuevo poder se manifiesta más bien en la organización del espacio y el tiempo, en la disciplina de las conductas en las diversas instituciones de la sociedad actual (cárceles, internados, escuelas, fábricas, etc.), y en los discursos de las ciencias humanas y sociales

${ }^{1}$ N. Fraser, "Foucault on Modern Power: Empirical Insights and Normative Confusions”, Praxis International, vol. 1, n 3 (1981), 272-287. Reeditado en N. Fraser, Unruly Practices: Power, Discorse, and Gender in Contemporary Social Theory, Minneapolis, University of Minnesota Press, 1989. 
que proporcionan la legitimación teórica de esas prácticas disciplinarias. Por último, las consecuencias prácticas de estos hallazgos eran, para Fraser, igualmente valiosas: Foucault permitía descartar formas erróneas y anticuadas de enfocar la acción política, por ejemplo todas las versiones del marxismo que reducen de manera simplista el poder a poder de clase, o los planteamientos de cierta izquierda (liberal o anarquista) empeñada en creer que el poder emana en exclusiva de esa institución centralizada y jerárquica que es el Estado. ${ }^{2}$ En contraste con estos enfoques, más o menos conscientemente deudores de la anticuada concepción represiva, la obra de Foucault parecía conectar mejor con la sensibilidad política de esa "nueva izquierda" que, desde la década de 1960, había introducido nuevas demandas y había favorecido la emergencia de nuevos actores políticos, como el movimiento estudiantil, las minorías sexuales o los colectivos feministas.

Hasta aquí las empirical insights de la teoría foucaultiana del poder. Pero ¿qué sucede con las normative confusions? Estas, en opinión de Fraser, no eran menos importantes que los hallazgos empíricos, que por su culpa quedaban algo deslucidos. El problema era que Foucault nunca aclaraba en nombre de qué realizaba su crítica del poder, ni lograba justificar por qué sus opciones teóricas y políticas eran preferibles a aquellas que criticaba. $\mathrm{Y}$ es que Foucault había decidido enfocar su teoría del poder poniendo sistemáticamente entre paréntesis la cuestión de la legitimidad o de la aceptabilidad racional: "la cuestión del poder - leemos, entre los innumerables textos que podríamos citar, en una entrevista de 1976- tiene que abordarse no tanto en términos de justicia como en términos de tecnología, de táctica y estrategia." ${ }^{3}$ Es decir: lo que importa es comprender cómo funciona el poder en las sociedades contemporáneas, y no si existen en estas sociedades formas más o menos legítimas de poder, o en qué condiciones el poder es legítimo o no lo es. Por supuesto, nada habría que objetar a este enfoque puramente descriptivo si las investigaciones de Foucault fuesen "axiológicamente neutrales", en el sentido de Max Weber. Pero lo cierto es que Foucault no desarrolla una teoría axiológicamente neutral, aunque a veces lo parezca o lo sostenga. ${ }^{4}$ Más bien al contrario, los textos de Foucault muestran de un modo más o menos explícito una oposición radical a

${ }^{2}$ Cf. M. Foucault, Hay que defender la sociedad, Tres Cantos, Akal, 2003, lección primera.

${ }^{3}$ M. Foucault, "Las relaciones de poder penetran en los cuerpos", en Microfísica del poder, Madrid, La Piqueta, 1991, p. 154.

${ }^{4}$ M. Foucault, El orden del discurso, Barcelona, Tusquets, 2011, pp. 56-57: "El humor genealógico será el de un positivismo alegre”. 
determinadas formas de poder en la sociedad contemporánea: el Estado, las instituciones psiquiátricas, la policía, etc. Ahora bien, si Foucault prescinde de conceptos como validez, legitimidad, aceptabilidad racional, etc., ya no puede explicar qué tiene de malo el poder que él critica (el que ejercen la policía, la cárcel o los psiquiatras), ni justificar por qué él mismo se sitúa a un lado y no a otro en las luchas sociales y políticas. Fraser resumía su crítica con esta frase: "lo que Foucault necesita, y lo necesita desesperadamente, son criterios normativos para distinguir las formas aceptables e inaceptables de poder". 5

Poco después, Axel Honneth y Jürgen Habermas asumirían y desarrollarían estos argumentos de Nancy Fraser para fabricar el arsenal que habrían de emplear en su polémica con la creciente y difusa constelación de los autores denominados "postmodernos". ${ }^{6} \mathrm{Y}$ sin duda las conocidas críticas de Fraser, Honneth o Habermas a la obra de Foucault son contundentes, pero se refieren a los escritos de la década de 1970, muy marcados por una visión de la sociedad moderna como una sociedad implacablemente opresiva y disciplinaria, y por el antihumanismo que Foucault había heredado del estructuralismo en la década anterior. Ahora bien, en los últimos años la obra de Foucault parece dar un giro que afecta a sus fundamentos normativos: sus escritos de la década de 1980 muestran un interés creciente por cuestiones éticas y una inesperada reivindicación de la Ilustración y de la obra de Kant. Este giro parece indisociable de una rehabilitación de la subjetividad, que la filosofía anterior de Foucault había relegado a una especie de epifenómeno de las epistemes o marcos cognitivos de cada época, o de las prácticas disciplinarias de la sociedad moderna. ${ }^{7}$ Cabe preguntarse, entonces, si son aplicables los argumentos de Fraser o Habermas a este último Foucault, o si, por el contrario, los escritos de la década de 1980 superan de algún modo ese déficit normativo que estos críticos habían detectado en los escritos de las décadas anteriores.

La primera de las dos innovaciones teóricas que encontramos en los últimos escritos de Foucault es una ética del "cuidado de sí” que se inspira en

${ }^{5}$ N. Fraser, op. cit., p. 33.

${ }^{6}$ A. Honneth, Kritik der Macht, Frankfurt a.M., Suhrkamp, 1982; J. Habermas, Der philosophische Diskurs der Moderne, Frankfurt a.M., Suhrkamp, 1985.

${ }^{7}$ Cf. M. Foucault, "El retorno de la moral”, en Estética, ética y hermenéutica, Barcelona, Paidós, 1999 , p. 382. 
el mundo antiguo y que constituye el tema de los volúmenes segundo y tercero de la Historia de la sexualidad, publicados en 1984. En Grecia y Roma existió una ética del cultivo personal de los afectos y los deseos, y del cultivo de la autonomía personal frente a los afectos y los deseos, que más tarde habría sido suprimida por el cristianismo - al que ya no interesa el cultivo de sí, sino más bien la negación de uno mismo- - posteriormente por las instituciones pedagógicas, médicas, psiquiátricas, etc. del mundo moderno. Pero la investigación de Foucault no solo tiene un propósito histórico, sino que reivindica para nuestra propia época esa ética antigua, que permitiría poner en movimiento o dinamizar prácticas que estarían bloqueadas por los dispositivos culturales e institucionales del cristianismo primero, y de la modernidad después. ${ }^{8}$ El siguiente pasaje de una entrevista de 1984 alude a este objetivo práctico de la investigación histórica sobre la ética del cuidado de sí:

Las relaciones de poder tienen un alcance extraordinario en las relaciones humanas. Ahora bien, eso no quiere decir que el poder político está en todas partes, sino que en las relaciones humanas se da todo un haz de relaciones de poder, que se pueden ejercer entre individuos, en el seno de una familia, en una relación pedagógica, o en el cuerpo político. Este análisis de las relaciones de poder constituye un campo extraordinariamente complejo. Tal análisis se encuentra en ocasiones con lo que cabe denominar hechos o estados de dominación, en los que las relaciones de poder, en lugar de ser móviles y permitir a los diferentes intervinientes una estrategia que las modifique, se encuentran bloqueadas y fijadas. Cuando un individuo o un grupo social llegan a bloquear un campo de relaciones de poder, volviéndolas inmóviles y fijas, e impidiendo toda reversibilidad de movimiento (mediante instrumentos que pueden ser tanto económicos como políticos o militares) estamos ante lo que se puede denominar un estado de dominación. (...) En semejante situación las prácticas de libertad no existen o existen solo unilateralmente, o están sumamente acotadas y limitadas. ${ }^{9}$

Este pasaje traza cierta continuidad entre la teoría del poder de los años setenta y la teoría ética de los ochenta. El poder - tal como sostiene Foucault al menos desde Vigilar y castigar - recorre sin excepción todas las relaciones sociales, pero cabe hacer distinciones que pueden adquirir un significado normativo: por ejemplo, la distinción entre el poder que se mueve libremente y la dominación, que es un poder fijado, detenido o bloqueado. Si la ética antigua del cuidado de sí es interesante no solo como objeto de

${ }^{8}$ M. Foucault, "La ética del cuidado de sí como práctica de la libertad", en Obras esenciales, vol. 3, Barcelona, Paidós, 1999, p. 394; M. Foucault, El origen de la hermenéutica de sí, Madrid, Siglo XXI, 2016, p. 48; M. Foucault, Historia de la sexualidad, vol. 2, Madrid, Siglo XXI, 1987, p. 25, p. 31.

${ }^{9}$ M. Foucault, "La ética del cuidado de sí como práctica de la libertad”, op. cit., p. 395. 
estudio histórico, sino también como una propuesta para nuestra propia época, es porque el cuidado de sí permite desbloquear prácticas bloqueadas y establecer "el mínimo posible de dominación"10 en el uso, estrictamente personal, de los placeres. Naturalmente, esta contraposición entre el poder móvil y el poder bloqueado no tiene nada que ver con la contraposición entre poder legítimo e ilegítimo, o justo e injusto. Estas distinciones estarían, pues, tan ausentes de esta entrevista publicada en el último año de la vida de Foucault como de toda su obra anterior. Sin embargo, cuando de lo que se trata es de la ética individual y el uso de los placeres no tendría sentido reprochar a Foucault un déficit normativo, precisamente porque en este terreno la distinción entre lo legítimo y lo ilegítimo no es relevante. Lo que defiende Foucault es, pues, inobjetable: la ética del cuidado de sí se justifica porque desbloquea opciones personales que ni la religión cristiana, ni el Estado, ni los restantes dispositivos institucionales y culturales de la sociedad moderna tienen derecho a fiscalizar o reprimir. Ahora bien, observemos que, interpretada de este modo, esta ética presupone una filosofía política que seguramente no es la que esperamos encontrar en un autor como Foucault: el liberalismo político, del que proceden ideas tan básicas como la distinción entre la esfera privada y la esfera pública o la defensa de los derechos individuales frente al Estado y de las libertades individuales frente a la tiranía de la sociedad. Como propuesta normativa, la ética del cuidado de sí sería entonces una versión actualizada (y quizás erotizada) del ensayo Sobre la libertad de John Stuart Mill. ¿Cabe concluir, por tanto, que Foucault resuelve en sus últimos textos el déficit normativo de su obra anterior asumiendo, siquiera de manera tácita, las categorías básicas del pensamiento social y político liberal? Esta conclusión resultaría tranquilizadora para los lectores menos seducidos por el potencial subversivo y anárquico de este autor, pero sería seguramente una conclusión precipitada y errónea. ${ }^{11} \mathrm{Y}$ es que la conexión de la ética del cuidado de sí con el liberalismo político no sería suscrita por Foucault, porque el liberalismo no es, ni mucho menos, la filosofía política que se destila de su obra, ni siquiera en los escritos del último periodo. ¿Cuál es, entonces, esa filosofía política?

Para responder a esta pregunta es útil analizar la otra innovación teórica de los escritos de los últimos años, a saber: la reivindicación de la Ilustra-

${ }^{10}$ Ibíd., p. 412.

${ }^{11}$ Cf. J. Fortanet, "Sobre la lectura rortyana de Michel Foucault", Contrastes. Revista Internacional de Filosofía, vol. XIV (2009), pp. 99-117. Fortanet contrapone las lecturas liberales de Foucault, especialmente difundidas en Estados Unidos, a las lecturas anarquizantes y nietzscheanas que han prevalecido siempre en la propia Francia. 
ción y de la corriente alemana de filosofía social que se extiende desde Kant hasta Habermas pasando por Hegel, Max Weber y la Escuela de Frankfurt. Son muy importantes dos conocidos textos homónimos de 1983: la transcripción de un seminario sobre el ensayo de Kant ¿Qué es la Ilustración?, y una conferencia del mismo título impartida en la universidad de Berkeley. ${ }^{12}$ En ambos textos Foucault sitúa a Kant en el origen del tipo de filosofía que él mismo quiere cultivar, y que se centra sobre todo en dos temas: la actualidad y la revolución. La actualidad, el propio presente histórico, el mundo social en el que vivimos, es el tema que la Ilustración elevó por primera vez a objeto de investigación filosófica, convirtiéndolo en la materia de una "ontología del presente" u "ontología de la actualidad" que, desde finales del siglo XVIII, se ha ganado un puesto propio junto a las más clásicas ramas de la filosofía. Foucault presenta esta ontología del presente como una alternativa al proyecto kantiano de una crítica epistemológica de la razón:

Considero que Kant ha fundado las dos grandes tradiciones críticas entre las cuales se ha dividido la filosofía moderna. Digamos que en su gran obra crítica Kant ha planteado, fundado, esta tradición de la filosofía que plantea la cuestión de las condiciones de posibilidad de un conocimiento verdadero (...). Pero existe en la filosofía moderna y contemporánea otro tipo de cuestión, otro modo de interrogación crítica (...). Esta otra tradición crítica plantea las siguientes preguntas: “¿Qué es nuestra actualidad? ¿Cuál es el campo actual de experiencias posibles?” (...) Se trata de lo que se podría denominar una ontología del presente, una ontología de nosotros mismos (...), una ontología de la actualidad; es esta la forma de filosofía que, de Hegel a la Escuela de Frankfurt pasando por Nietzsche y Max Weber, ha fundado una forma de reflexión en la cual he intentado trabajar. ${ }^{13}$

Ahora bien, según Foucault este interés del pensamiento crítico por la actualidad histórica es indisociable de otra cuestión más específicamente política: la cuestión de la revolución. Pensar la actualidad parece implicar pensar también la revolución, o incluso asumir un compromiso con la revolución. Foucault conecta ambas cuestiones en una amalgama sugerente, aunque no demasiado precisa, que le permite presentarse como seguidor de Kant en tanto que teórico de la actualidad y también en tanto que partidario de la revolución:

El otro rostro de la actualidad que Kant encontró es la revolución (...). [Pero] la cuestión para la filosofía no es determinar cuál es la parte de la revolución que convendría preservar y poner de relieve como modelo. Es saber lo que hay que hacer con esa voluntad de revolución, con ese "entusiasmo" por la revolución que es algo distinto a la misma empresa revolucionaria. Las dos preguntas “¿Qué es la Ilustración?” y “¿Qué

${ }^{12}$ Ambos publicados en M. Foucault, Sobre la Ilustración, Madrid, Tecnos, 2003.

${ }^{13}$ Ibíd., p. 69. 
hacer con la voluntad de revolución?" definen entre ambas el campo de interrogación filosófica que apunta a lo que somos en nuestra actualidad. ${ }^{14}$

A decir verdad, es discutible - y en seguida veremos que el propio Foucault no siempre estuvo muy convencido de esto- que Kant se sitúe realmente en el origen de esa "ontología de la actualidad" o filosofía social alemana que Foucault reivindica, o incluso que pertenezca claramente a ella. ${ }^{15}$ Pero en nuestro contexto, nos importa más detenernos en esa conexión, que Foucault cree reconocer en la obra de Kant y que asume también en su propia obra, entre la ontología del presente y el compromiso con la revolución. Y es que, a pesar de que es el propio Foucault quien reclama esta filiación kantiana e ilustrada, hay en estos escritos de la última época una diferencia sustancial con Kant, que atañe una vez más al fundamento normativo de las ideas foucaultianas.

La expresión "entusiasmo por la revolución" que Foucault emplea en estos pasajes alude, obviamente, a El conflicto de las facultades. En este ensayo de 1798, Kant interpretaba la reacción entusiasta que la Revolución francesa había provocado entre el público ilustrado, incluso entre el público menos directamente afectado por los acontecimientos, como un indicio del progreso moral de la humanidad. Y es que para Kant era un indicio de progreso moral el hecho de que los hombres fuesen capaces de ponerse de parte de una causa justa, como sin duda lo era la causa de los revolucionarios de 1789 , incluso si no ganaban nada con ello e incluso si la manifestación de su posicionamiento político podía acarrear algún riesgo personal. "La revolución - escribe Kant en el pasaje decisivo, que Foucault cita y comenta- (...) encuentra en el ánimo de todos los espectadores (...) una simpatía conforme al deseo y que colinda con el entusiasmo (...), la cual no puede tener otra causa que una disposición moral en el género humano". ${ }^{16}$ Pero Foucault apenas dice nada de las razones que motivaban el entusiasmo revolucionario de los ilustrados. Para él, lo importante es constatar que ya en la filosofía de Kant aparecen juntos los dos rasgos inseparables que definen a la Ilustración: el interés por el presente y el compromiso con la revolución. Sin embargo, esta interpretación del pensamiento kantiano pasa por alto lo esencial. Es verdad que Kant se entusiasmó con la gran Revolución

${ }^{14}$ Ibíd., p. 68.

${ }^{15}$ Axel Honneth, por ejemplo, remonta esta línea más bien a Rousseau. Cf. A. Honneth, "Kritische Theorie. Vom Zentrum zur Peripherie einer Denktradition”, en Die zerrissene Welt des Sozialen, Frankfurt am Main, Suhrkamp, 1999.

${ }^{16}$ Ak VII 85. 
de su época, pero no porque albergase una "voluntad de revolución" que se seguiría inexorablemente de su condición de filósofo ilustrado o —si aceptamos la interpretación que propone Foucault - de "ontólogo de la actualidad". El entusiasmo de Kant estaba motivado más bien por el tipo de poder político que la Revolución aspiraba a instaurar. Así lo muestra con toda claridad la continuación (que Foucault no cita) de ese mismo pasaje de El conflicto de las facultades en el que Kant confesaba su entusiasmo revolucionario:

En esta causa moral confluyen dos cosas: en primer lugar, el derecho a que un pueblo no haya de verse obstaculizado por poder alguno para darse una constitución civil tal como le parezca bien a él mismo; en segundo lugar, el fin (que al mismo tiempo es un deber) de que aquella constitución de un pueblo solo sea jurídica y moralmente buena en sí (...), cuando su naturaleza sea de tal índole que pueda evitar con arreglo a principios la guerra ofensiva, constitución que no puede ser sino la constitución republicana $(\ldots) .{ }^{17}$

Dos son, pues, las razones del entusiasmo ilustrado por la Revolución francesa. La primera es el hecho de que un pueblo se sacuda el yugo del absolutismo para darse a sí mismo democráticamente la constitución política "que le parezca bien"; y la segunda — but not least_ es la circunstancia de que esa constitución pertenece a un tipo muy definido: se trata de una Constitución republicana. En La paz perpetua, un escrito un poco anterior (1795), Kant ya había precisado el significado de este concepto. Solo cabe considerar "republicana" a la Constitución que recoge los principios de libertad e igualdad, siendo la primera "la facultad de no obedecer ninguna ley exterior sino en la medida en que he podido darle mi consentimiento", y consistiendo la segunda en "la relación entre los ciudadanos según la cual nadie puede imponer a otro una obligación jurídica sin someterse él mismo también a la ley y poder ser, de la misma manera, obligado a su vez". ${ }^{18}$

${ }^{17}$ Ibíd. Foucault menciona estas razones para el entusiasmo revolucionario de Kant, pero no como justificaciones de ese entusiasmo o de la propia revolución: "la constitución política voluntariamente elegida por los hombres y una constitución política que evite la guerra son, ambos, los [elementos] que definen el proceso mismo de la Aufklärung”. M. Foucault, Sobre la Ilustración, op. cit., p. 65.

${ }^{18}$ Ak VIII, 349-350. No necesitamos analizar aquí el tercer rasgo que define la Constitución republicana: la "dependencia de todos respecto a una única legislación común”, a la que se encuentran sometidos "en cuanto súbditos". El propio Kant desarrolla este concepto menos que los otros dos, argumentando que "no necesita explicación". Ciertamente, a la luz del texto kantiano la única diferencia respecto de la igualdad jurídica parece consistir en que, cuando se refiere a la "dependencia", Kant habla de súbditos, y no de ciudadanos. Siguiendo a J. Abellán: "En torno al concepto de ciudadano en Kant”, en: R. Aramayo, J. Muguerza, C. Roldán (eds.): La paz y el ideal cosmopolita de la Ilustración, Madrid, Tecnos, 
El consentimiento democrático y la igualdad ante la ley: tales son los principios de la única forma de Constitución que nace "en la pura fuente del concepto de derecho", y por tanto de la única que puede considerarse plenamente legítima desde un punto de vista jurídico y político. Un tipo de Constitución que idealmente, y salvando las distancias, corresponde aproximadamente a lo que hoy entendemos por Estado democrático de derecho. ${ }^{19}$

Si los ilustrados europeos de finales del siglo XVIII abrazaron la causa de la Revolución, fue (según Kant) porque la Revolución prometía institucionalizar estos principios normativos: libertad política e igualdad ante la ley. Lo determinante para Kant (y para la Ilustración en general) no era, pues, esa presunta "voluntad de revolución" que Foucault atribuye al pensamiento ilustrado, sino precisamente la legitimidad del poder que surgiría de la revolución, si ésta tenía éxito. En cambio, la legitimidad de la revolución misma, en tanto que conculcación violenta del orden jurídico y político vigente, era para Kant un asunto mucho más espinoso. Así lo muestran algunos elocuentes pasajes de la Metafísica de las costumbres que recuerdan mucho más al pensamiento absolutista de Hobbes que a las ideas de Locke sobre el derecho del pueblo a una revolución contra un gobernante despótico:

Si un súbdito que hubiera meditado sobre el origen último del Estado quisiera resistirse a la autoridad en ese momento reinante, sería castigado, aniquilado o desterrado (como un proscrito, exlex) según las leyes de tal autoridad, es decir, con todo derecho. (...) De aquí se sigue, pues, el siguiente principio: el soberano en el Estado tiene ante el súbdito solo derechos y ningún deber (constrictivo) (...) Es lícito al súbdito quejarse de [la] injusticia (...), pero no oponer resistencia (...). Contra la suprema autoridad legisladora del Estado no hay, por tanto, resistencia legítima del pueblo". ${ }^{20}$

1996, podemos interpretar este principio como la introducción, ya en el propio concepto de Constitución republicana, de la distinción entre los ciudadanos, dotados de derechos políticos, y los súbditos (niños, mujeres y asalariados) que carecen de ellos. Esta interpretación parece confirmarse en la sección 46 de la Metafísica de las Costumbres, (Ak VI 314), en la que Kant define la condición de ciudadano por la libertad, la igualdad y la "independencia civil", que consiste en "no agradecer la propia existencia y conservación al arbitrio de otro".

${ }^{19}$ Las diferencias, por otro lado, no son menores: Kant no reconoce derechos políticos a todos los miembros del Estado, y además piensa que un gobierno puede ser republicano sin ser democrático. De hecho, el gobierno de un autócrata ilustrado puede ser más republicano que un régimen democrático. Pero podemos ignorar aquí estas peculiaridades de la filosofía política kantiana, que en buena medida se deben al contexto social en el que escribía Kant.

${ }^{20} \mathrm{Ak}$ VI, 318-320. En este mismo espíritu, Kant califica la ejecución de un rey de "crimen que permanece perpetuamente y nunca puede expiarse (...), y [que] parece asemejarse a lo que los teólogos llaman el pecado que no puede personarse en este mundo ni en el otro" (Ak VI 320n). 
La contradicción de estos pasajes con la profesión de entusiasmo revolucionario que antes leíamos en El conflicto de las facultades es tan evidente que fácilmente nos sentimos tentados a buscarle alguna explicación sociológica o psicológica, pero en cualquier caso extra-filosófica. Si cedemos a esa tentación, podemos interpretar que las loas hobbesianas a la autoridad tendrían como objetivo ocultar a las autoridades prusianas las peligrosas ideas revolucionarias de un Kant secretamente jacobino; o bien al revés, interpretaremos el entusiasmo revolucionario de Kant como una afección pasajera que solo afloraría intermitente e inconsistentemente en algunos textos (en alguna recóndita nota al pie de La religión dentro de los límites de la mera razón, ${ }^{21}$ o en la ya citada página de El conflicto de las facultades), para quedar pronto desmentida y embridada por un culto al Estado típicamente prusiano. Pero en realidad no necesitamos recurrir a ninguna de estas dos explicaciones para disolver la contradicción de estos textos kantianos, pues ésta puede conciliarse (al menos parcialmente) de un modo más simple. Basta con distinguir entre los fines y los medios de la revolución (en este caso, de la Revolución francesa), y atribuir a Kant la defensa de los primeros y el rechazo (con matices) de los segundos. Kant era partidario de reformar las constituciones y de evitar las revoluciones. Éste es el sentido de esas célebres páginas del ensayo sobre la Ilustración en las que Kant defiende la irrestricta libertad de crítica a condición de que el público ilustrado esté, al mismo tiempo, dispuesto a obedecer la autoridad del Estado. Si el lema del monarca ilustrado "razonad cuanto queráis y sobre lo que queráis, pero obedeced" no se reduce a una mera expresión de cinismo, es porque la crítica del público ilustrado no solo se dirige contra el monarca, sino al mismo tiempo también a él, con la esperanza de que la fuerza de las razones incline la voluntad del gobernante en la dirección correcta. ${ }^{22}$ Así lo muestra también el pasaje de la Metafísica de las costumbres con el que Kant concluye su enfática proscripción de toda subversión violenta: "Un cambio en una constitución política (defectuosa), que bien puede ser necesario a veces, solo puede ser introducido por el soberano mismo mediante reforma, pero no por el pueblo, por consiguiente no por revolución $(\ldots) "{ }^{23}$

Foucault se equivoca, por tanto, cuando apela a Kant para argumentar que "la cuestión para la filosofía no es determinar cuál es la parte de la re-

${ }^{21} \mathrm{Ak}$ VI, 188n.

${ }^{22}$ Ak VIII 41. Cf. sobre esto I. Fetscher, "Immanuel Kant und die Französische Revolution", en Z. Batscha (ed.), Materialien zu Kants Rechtsphilosophie, Frankfurt am Main, Suhrkamp, 1976.

${ }^{23}$ Ak VI 321-322. 
volución que convendría preservar y poner de relieve como modelo." ${ }^{24}$ Para Kant esa era precisamente la cuestión principal. La Revolución francesa podía justificarse por sus fines, aunque no por sus medios. Y esta distinción entre la legitimidad de los fines de la Revolución francesa y la ilegitimidad de sus medios permite comprender por qué Kant, a diferencia de otros ilustrados alemanes (pronto convertidos en reaccionarios), no abjuró nunca de la revolución a pesar de sus mayores excesos, es decir, a pesar del Terror. En efecto, la elección que el público ilustrado debía hacer no era simplemente una elección a favor o en contra de la revolución sin más, ni — por regresar de nuevo a los términos escogidos por Foucault - una elección entre entregarse con alegría a una "voluntad de revolución" supuestamente consustancial a la Ilustración o más bien reprimirla. Kant no se posiciona a favor o en contra de una genérica voluntad de revolución, sino a favor de los objetivos de esa revolución en concreto, la Revolución francesa, que aspiraba a institucionalizar una Constitución republicana. Por eso Kant nunca justifica el Terror, aunque sí lo explica y en cierto modo lo disculpa. La barbarie desatada por las revoluciones es también la consecuencia de una opresión que, de tanto tratar a los hombres como bestias, termina convirtiéndolos en tales:

A los profetas judíos les resultaba muy fácil predecir el carácter inminente no solo de la decadencia, sino de la plena desintegración de su Estado, ya que eran ellos mismos los autores de tal destino. (...) Nuestros políticos hacen exactamente lo mismo en su esfera de influencia, siendo igualmente afortunados en sus presagios. Aseguran que se ha de tomar a los hombres tal como son y no como los pedantes ajenos al mundo o los soñadores bienintencionados imaginan que deben ser. Pero ese como son viene a significar en realidad lo que nosotros hemos hecho de ellos merced a una coacción injusta y mediante alevosas maquinaciones inspiradas al gobierno, esto es, testarudos y proclives a la rebelión; así las cosas, por supuesto que si aflojan un poco las riendas, acontecen trágicas consecuencias que cumplen los vaticinios de aquellos estadistas presuntamente perspicaces. ${ }^{25}$

\section{III}

La filosofía política kantiana no está libre de tensiones, pero no es este el lugar de ahondar en ellas. Nos basta señalar que, con independencia del juicio que merezca la compleja relación de Kant con la Revolución, la posición de Foucault es, en cualquier caso, precisamente la contraria de la posición

${ }^{24}$ M. Foucault, Sobre la Ilustración, op. cit., p. 68.

${ }^{25}$ Ak VII 80. 
kantiana. Foucault deriva la "voluntad de revolución" simplemente de la "ontología del presente", es decir: conecta el interés teórico por comprender el funcionamiento del poder moderno con el compromiso práctico con la sublevación contra ese poder. Pero Foucault parece desentenderse de la cuestión de la legitimidad o ilegitimidad del poder contra el cual se alza la revolución (la francesa u otras), porque implícitamente supone que todo poder constituido es una forma de dominación (un poder bloqueado, fijo, inerte), y es por tanto ilegítimo; y acoge con entusiasmo toda "voluntad de revolución" como tal, porque implícitamente supone que toda sublevación contra un poder constituido es una forma de desbloquear la dominación, y por tanto es un contrapoder legítimo. Y todo esto parece ser así sean cuales sean los principios del poder constituido, y sean cuales sean los objetivos del contrapoder revolucionario.

Estas consideraciones bastarían para poner en cuestión la verosimilitud de la filiación kantiana que Foucault reclama en sus últimos escritos. Pero a decir verdad, el propio Foucault era consciente de lo mucho que le separaba de Kant y de la Ilustración. Una conferencia titulada ¿Qué es la crítica?, pronunciada en 1978 (es decir, en un periodo de tránsito desde las investigaciones sobre el poder a la preocupación por la ética y la reivindicación de la Ilustración) ofrece una interpretación del pensamiento kantiano mucho más afín al espíritu de la obra de Foucault, y al mismo tiempo (y por eso mismo) mucho menos favorable a Kant. Con su talento para las formulaciones concisas y brillantes, en aquella conferencia Foucault definía la actitud crítica como el "arte de la inservidumbre voluntaria". ${ }^{26}$ Este arte o esta actitud corresponden a la mentalidad de la Ilustración, y tienen precedentes en la Reforma luterana, que se sacudió la servidumbre religiosa de la Edad Media, y en las teorías del derecho natural de los siglos XVI y XVII que enarbolaron por primera vez la idea de "unos derechos universales e imprescriptibles a los cuales todo gobierno, sea cual sea (...), deberá someterse" ${ }^{27}$ Claro está que en las filas de los pensadores críticos tenemos que situar también a Kant, pero en este escrito de 1978 su figura desempeña un papel más cuestionable. Lejos de ser el pionero de la "ontología del presente" y de la "voluntad de revolución", Kant aparece ahora como el filósofo que habría distorsionado o pervertido o confundido el arte de la insumisión al desviar la actitud crítica hacia cuestiones relacionadas con la validez y los límites del conocimiento. Se produce en la obra de Kant, pues, un "des-

${ }^{26}$ M. Foucault, “¿Qué es la crítica?”, Daimon. Revista de filosofía, n¹1 (1995), p. 8.

${ }^{27}$ Ibíd., p. 7. 
fase" o "una oposición (...) entre el análisis de la Aufklärung y el proyecto crítico", ${ }^{28}$ que en su versión más genuina solo cabe interpretar como un proyecto, más político que teórico, de insumisión al poder. Y como consecuencia de esta desvirtuación de la verdadera actitud crítica, que sería la actitud radicalmente insumisa, la Ilustración kantiana y postkantiana se habría entretenido en la investigación (presumiblemente acrítica y servil) de las condiciones y los límites del conocimiento válido, o peor aún: de las condiciones y límites del poder legítimo. Contra esta tergiversación kantiana de la actitud crítica, en este escrito anterior a su ambiguo giro ilustrado Foucault aún reivindicaba, como siempre había hecho, una consecuente omisión sistemática de las cuestiones normativas:

Lo que buscamos (...) no es saber lo que es verdadero o falso, fundado o no fundado, real o ilusorio, científico o ideológico, legítimo o abusivo. Buscamos saber cuáles son los lazos, las conexiones que pueden ser señaladas entre mecanismos de coerción y elementos de conocimiento (...). Por eso (...) [se puede operar] una reducción sistemática del valor, es decir, una neutralización de los efectos de legitimidad (...). Se trata así de evitar hacer jugar de entrada la perspectiva de la legitimación, como lo hacen los términos de conocimiento o de dominación..$^{29}$

No es extraño que al Foucault todavía inmerso en su proyecto genealógico o en su teoría del poder Kant le pareciera un aliado ambiguo o poco fiable. Lo extraño es, más bien, que pocos años después Foucault olvidase estas reticencias y viera en Kant a un autor tan afín a sus propios intereses. Y es que ese "desfase" kantiano entre Ilustración e insumisión, que el texto de 1978 parece despreciar, marca simplemente la distancia entre una filosofía que quiere dar respuesta a los problemas de la validez del conocimiento y la legitimidad del poder, y otra filosofía que se desentiende de ellos.

\section{IV}

Quizás estamos ya en condiciones de responder a la pregunta que nos hacíamos hace algunas páginas: ¿supera Foucault en los años ochenta el déficit normativo criticado en su obra anterior? No lo creo. Como ya sucediera en el contexto de la ética del cuidado de sí, cabría pensar que, al encomendarse a Kant y olvidarse un poco de Nietzsche, Foucault haría suyo un marco normativo racionalista y políticamente liberal, enteramente ausente de su filosofía anterior. Pero a pesar de la reorientación hacia la ética, y

\footnotetext{
${ }^{28}$ Ibíd., p. 13, p. 9.

${ }^{29}$ Ibíd., p. 14.
} 
pese a su declarada filiación kantiana e ilustrada, más bien se diría que los últimos textos de Foucault reproducen todos los problemas normativos de su obra anterior. En las antípodas de Kant, la precipitada conexión de la "ontología de la actualidad" con la "voluntad de revolución" parece reducir la filosofía política de Foucault a una sola idea, por lo demás difícilmente aceptable: la idea de que quien se interese por el presente debe asumir, como única posición política consecuente, la defensa de la revolución por la revolución, sea cual sea el objetivo o las aspiraciones de ésta, con tal de que contribuya a subvertir la dominación vigente y a desbloquear el flujo del poder social. Pero esta apología de la subversión como fin en sí misma resulta en un pensamiento político bastante inconcreto y más bien inútil. Con razón ha sido criticada muchas veces, antes y después de los argumentos de Nancy Fraser a los que hemos aludido al comienzo de este artículo. Recientemente José Luis Pardo señaló en sus Estudios del malestar (2016) que en Foucault hay "un derecho universal a la sublevación y una sospecha universal contra todo poder. De manera que la única posición digna sería la sublevación permanente". ${ }^{30}$ Y hace casi medio siglo, en un famoso debate que mantuvo con Foucault, ya Noam Chomsky había protestado contra este craso irracionalismo político. ${ }^{31}$ Foucault argumentaba en aquella disputa que la lucha de clases proletaria - a la que entonces parecía adherirse, aunque años después afirmase no haber sido nunca marxista ${ }^{32}$ - no necesitaba ni podía justificarse en nombre, por ejemplo, de un ideal de justicia social. La lucha de clases debía concebirse simplemente como la aspiración del proletariado a la conquista del poder, al desbloqueo de la dominación burguesa, y los principios normativos, como la propia idea de justicia, no serían otra cosa que armas arrojadizas en ese combate entre la dominación y el contrapoder. Foucault resumía su posición con un sofisma lapidario: "Se hace la guerra para ganarla, no porque sea justa", ${ }^{33}$ mientras Chomsky señalaba la profunda inconsistencia de una filosofía política que renuncia a toda justificación normativa y repetía una y otra vez, con cierta irritación:

${ }^{30}$ J. L. Pardo, Estudios del malestar, Barcelona, Anagrama, 2016, p. 97-98.

${ }^{31}$ N. Chomsky y M. Foucault, La naturaleza humana: justicia versus poder, Madrid, Katz, 2006.

${ }^{32}$ M. Foucault, "Estructuralismo y postestructuralismo”, en Estética, ética y hermenéutica, Barcelona, Paidós, 1999, p. 312. Sobre los diversos (y quizás oportunistas) cambios ideológicos de Foucault, cf. J. L. Moreno Pestaña, Foucault y la política, Madrid, Tierradenadie, 2011.

${ }^{33}$ N. Chomsky y M. Foucault, La naturaleza humana: justicia versus poder, op. cit., p. 73. 
"no estoy de acuerdo." Comenzaba entonces la década de 1970 y aún tardaría en llegar el giro ético de la producción foucaultiana más tardía, pero nada sustancial cambió, a este respecto, en los últimos escritos.

La vigencia de una filosofía puede juzgarse o bien por su actualidad o bien por su capacidad de convicción. Las ideas políticas de Foucault son vigentes porque son actuales, pero no porque sean convincentes. Son actuales, ciertamente, porque han calado en el discurso político más reciente - junto con las de otros autores pertenecientes a la amplia corriente del pensamiento postmoderno, o quizás simplemente nietzscheano-, de manera que hoy son casi lugares comunes la idea de que el poder está por todas partes y empapa sin hacer distinciones todas las relaciones sociales, o la idea de que todo poder constituido (eso que Foucault llama dominación) es más o menos inaceptable, mientras que todo contrapoder es bienvenido ya solo por ser un contrapoder y debería, en consecuencia, eclosionar sin trabas. Estas son tesis que conectan con la sensibilidad política de una sociedad en la que se reclama una constante movilización y refundación, y en la que se pretende que la actitud genuinamente crítica solo puede materializarse en la subversión de todo poder constituido y en la defensa de un permanente proceso constituyente. Pero con Kant, y contra Foucault, habría que recordar que aquello que nos permite decidir si una revolución es aceptable es la legitimidad de esa revolución y la ilegitimidad del poder contra el que se alza. Las ideas políticas de Foucault son desorientadoras porque omiten o silencian (aunque hagan a veces mucho ruido) esa distinción normativa, que seguramente es la distinción más importante.

\section{Bibliografía}

Abellán, J., "En torno al concepto de ciudadano en Kant”, en R. Aramayo, J. Muguerza, C. Roldán (eds.): La paz y el ideal cosmopolita de la Ilustración, Madrid, Tecnos, 1996.

Chomsky, N. y M. Foucault, La naturaleza humana: justicia versus poder, Madrid, Katz, 2006.

Fetscher, I., "Immanuel Kant und die Französische Revolution", en Z. Batscha (ed.), Materialien zu Kants Rechtsphilosophie, Frankfurt am Main, Suhrkamp, 1976.

Fortanet, J., "Sobre la lectura rortyana de Michel Foucault", Contrastes. Revista Internacional de Filosofía, vol. XIV (2009), pp. 99-117. Foucault, M., Historia de la sexualidad, vol. 2, Madrid, Siglo XXI, 1987. Foucault, M., Microfísica del poder, Madrid, La Piqueta, 1991. 
Foucault, M., “¿Qué es la crítica?”, Daimon. Revista de filosofía, n¹1 (1995), pp. 5-25.

Foucault, M., Estética, ética y hermenéutica, Barcelona, Paidós, 1999.

Foucault, M., Hay que defender la sociedad, Tres Cantos, Akal, 2003.

Foucault, M., Sobre la Ilustración, Madrid, Tecnos, 2003.

Foucault, M., El orden del discurso, Barcelona, Tusquets, 2011.

Foucault, M., El origen de la hermenéutica de sí, Madrid, Siglo XXI, 2016.

Fraser, N., "Foucault on Modern Power: Empirical Insights and Normative Confusions", Praxis International, vol. 1, no 3 (1981), 272-287. Reeditado en N. Fraser, Unruly Practices: Power, Discorse, and Gender in Contemporary Social Theory, Minneapolis, University of Minnesota Press, 1989.

Habermas, J., Der philosophische Diskurs der Moderne, Frankfurt a.M., Suhrkamp, 1985.

Honneth, A., "Kritische Theorie. Vom Zentrum zur Peripherie einer Denktradition", en Die zerrissene Welt des Sozialen, Frankfurt am Main, Suhrkamp, 1999.

Honneth, A., Kritik der Macht, Frankfurt a.M., Suhrkamp, 1982.

Kant, I., Beantwortung der Frage: Was ist Aufklärung? (1784), Ak VIII.

Kant, I., Die Religion inerhalb der Grenzen der blossen Vernunft (1793), Ak VI.

Kant, I., Zum ewigen Frieden (1795), Ak VIII.

Kant, I., Metaphysik der Sitten (1797), Ak VI.

Kant, I., Der Streit der Fakultäten (1798), Ak VII.

Moreno Pestaña, J.L., Foucault y la política, Madrid, Tierradenadie, 2011. Pardo, J.L., Estudios del malestar, Barcelona, Anagrama, 2016. 